Jurnal Ilmiah Matematika dan Pendidikan Matematika (JMP)

Vol. 10 No. 1, Juni 2018, hal. 53-66

ISSN (Cetak) : 2085-1456; ISSN (Online) : 2550-0422

\title{
ANALISIS ANTRIAN SINGLE CHANNEL SINGLE SERVER DENGAN LAYANAN BERKELOMPOK PADA KONEKSI INTERNET DI UNIVERSITAS ISLAM INDONESIA
}

\author{
Karina Noraprilia \\ Prodi Statistika, FMIPA, Universitas Islam Indonesia \\ knoraprilia@gmail.com \\ Atina Ahdika \\ Prodi Statistika, FMIPA, Universitas Islam Indonesia
}

\begin{abstract}
Internet is very important to support students in getting knowledge. However, internet access in college is sometimes not proportional to the number of users. Current speed of wireless network connection in Universitas Islam Indonesia (UII), named UIIAccess, is also not proportional to the number of users. Based on these problems, this research was conducted to study UIIAccess performance in providing internet service. The analysis used is single channel single server queuing model with bulk service. The result shows that traffic intensity of the system is 0.9694 indicating that the intensity of UIIAccess service is very solid. The queue performance shows that the average number of users in the system and waiting in the queue are respectively 32 and 11 users per minute, the average time spent by a user in the system and in the queue are consecutively 10.45574 and 3.63663 minutes. It indicates that the queue on UIIAccess is very crowded because of the imbalance between access speed and the number of users.
\end{abstract}

Keywords: bulk service, queuing model, queue performance, wireless network connection

\begin{abstract}
ABSTRAK. Internet merupakan hal yang sangat penting bagi mahasiswa dalam memperoleh pengetahuan. Namun, akses internet di perguruan tinggi kadang tidak sebanding dengan banyaknya pengguna. Kecepatan akses internet di Universitas Islam Indonesia (UII), yang dinamakan UIIAccess, juga tidak sebanding dengan banyaknya pengguna. Berdasarkan masalah tersebut, penelitian ini dilakukan untuk mempelajari kinerja UIIAccess dalam menyediakan layanan internet. Analisis yang digunakan adalah model antrian single channel single server dengan layanan berkelompok. Hasil penelitian menunjukkan bahwa intensitas antrian bernilai 0.9694 yang mengindikasikan bahwa intensitas layanan UIIAccess sangat padat. Kinerja antrian menunjukkan bahwa rata-rata jumlah pengguna di dalam sistem dan yang menunggu di antrian berturut-turut adalah 32 dan 11 pengguna per menit, rata-rata waktu yang dihabiskan oleh setiap pengguna di dalam sistem maupun di dalam antrian berturut-turut adalah 10.45574 dan 3.63663 menit. Hal ini mengindikasikan bahwa antrian pada UIIAccess sangat padat karena ketidakseimbangan antara kecepatan akses dengan jumlah pengguna.
\end{abstract}

Kata Kunci: layanan berkelompok, model antrian, kinerja antrian, koneksi internet 


\section{PENDAHULUAN}

Akses internet di Perguruan Tinggi (PT) merupakan hal yang sangat penting dikarenakan pentingnya bagi dosen, karyawan, atau mahasiswa dalam mengakses informasi secara cepat dan akurat. Bagi mahasiswa, internet sangatlah penting demi menunjang kebutuhannya dalam mendapatkan ilmu pengetahuan yang sekarang banyak bertebaran di internet.

Universitas Islam Indonesia (UII) sendiri menyediakan berbagai macam Sistem dan Teknologi Informasi (STI) untuk dapat digunakan oleh para dosen, karyawan dan mahasiswa dalam bertukar informasi melalui internet. Oleh karena pentingnya STI bagi Perguruan Tinggi pada tahun 1982 didirikan sebuah badan mengakomodasi perubahan dan perkembangan lingkungan pada bidang STI yang diberi nama Pusat Komputer UII. UII menyediakan fasilitas wifi yang dinamakan UIIAccess. Fasilitas ini dapat diaskses untuk seluruh civitas akademi UII. Kecepatan akses yang ditawarkan oleh UIIAccess ini yaitu hanya sebesar $1 \mathrm{Mbps}$ - 2 Mbps, dimana kecepatan akses tersebut sangatlah lambat jika dibandingkan dengan banyaknya pengguna UIIAccess. Dalam menggunakan UIIAccess ini setiap pengguna yang ada diberikan limit kapasitas penggunaan wifi yaitu sebesar 15 GB untuk 6 bulan penggunaan setiap penggunanya.

Kecepatan yang dimiliki oleh UIIAccess tidak sebanding dengan banyaknya pengguna wifi yang ada, maka dari itu ketika pengguna UIIAccess padat atau banyak pengguna maka kecepatan wifi tersebut menjadi tidak stabil dan terjadi antrian. Antrian terjadi dikarenakan kapasitas layanan yang ada tidak dapat menampung banyaknya kebutuhan pengguna akan layanan. Berdasarkan uraian di atas maka penulis ingin meneliti mengenai kinerja antrian yang ada pada UIIAccess.

Pada UIIAccess server dapat melayani pengguna sebanyak sekelompok (Bulk) pengguna dan server yang ada hanya satu, oleh karena itu model antrian yang digunakan dalam kasus UIIAccess ini yaitu Single Channel Single Server dengan Layanan Berkelompok/Bulk Service $\left(M / M^{B} / 1\right)$.

Model $\mathrm{M} / \mathrm{M}^{\mathrm{B}} / 1$ ini mempertimbangkan sistem antrian server tunggal dimana server mampu melayani sekelompok (Bulk) pelanggan atau lebih dari 
Bulk pelanggan pada saat yang sama. Setiap kali server menyelesaikan layanan, kemudian melayani sekelompok pelanggan berikutnya pada waktu yang sama. Diasumsikan bahwa laju pelayanan pelanggan adalah sebesar $\mu$ dan laju kedatangan pelanggan adalah sebesar $\lambda$.

\section{METODE PENELITIAN}

\subsection{Teori Antrian}

Antrian terjadi dikarenakan kapasitas pelayanan yang ada tidak mampu lagi untuk menampung kebutuhan pelanggan. Komponen dalam sistem antrian yaitu pelanggan masuk (in) kemudian pelanggan mengantri untuk dilayani (queue) setelah pelanggan selesai dilyani (server) maka pelanggan dapat meninggalkan layanan (out) seperti pada Gambar 1. Antrian itu sendiri tidak selalu berkaitan dengan pelanggan (orang) dapat berupa barang seperti contohnya yang terjadi di suatu pabrik, yang melayani yaitu mesin yang digunakan untuk membuat barang tersebut.

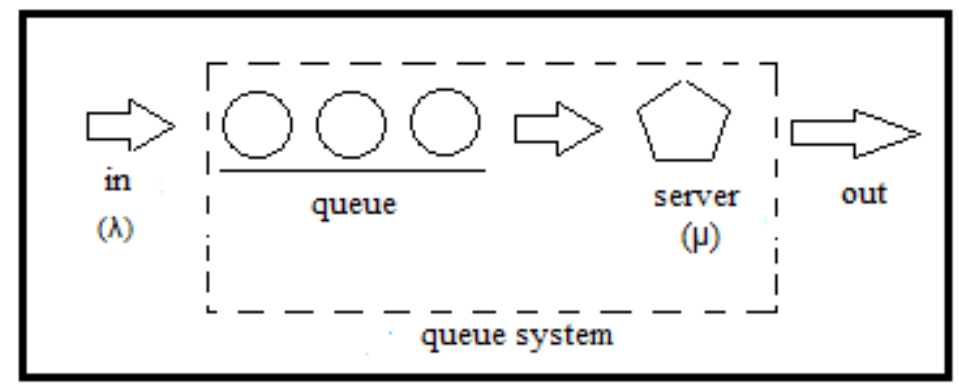

Gambar 1. Diagram Antrian

\subsection{Layanan Berkelompok}

Dalam model antrian $M / M^{B} / 1$ mempertimbangkan sistem antrian singleserver di mana server mampu melayani sekelompok (Bulk) pelanggan atau lebih pada saat yang sama. Setiap kali server menyelesaikan layanan, kemudian melayani Bulk pelanggan berikutnya pada waktu yang sama. Berikut merupakan simbol-simbol yang digunakan dalam model antrian Bulk Service. 
Tabel 1. Notasi dalam Model Antrian $M / M^{B} / 1$

\begin{tabular}{cl}
\hline Simbol & \multicolumn{1}{c}{ Keterangan } \\
\hline$\lambda$ & Laju kedatangan pengguna \\
$\mu$ & Laju layanan \\
$\rho$ & Intensitas antrian \\
$B$ & Ukuran kelompok (bulk) \\
$p$ & Peluang bahwa layanan melibatkan sekelompok $B$ \\
& pengguna \\
& Peluang bahwa layanan melibatkan seorang pengguna \\
& ketika minimal $B$ pengguna sedang dilayani; $p+q=$ \\
& 1 \\
& Laju layanan ketika sistem memuat $i$ pengguna dengan \\
& $i<B$ \\
& $v=\mu \cdot q$ adalah laju pengguna meninggalkan sistem \\
& sendiri ketika lebih dari $B$ pengguna sedang berada di \\
& dalam system \\
& $\delta=\mu \cdot p$ adalah laju sekelompok $B$ pengguna \\
& meninggalkan system \\
&
\end{tabular}

Pada penelitian yang dibahas oleh penulis ini mengacu terhadap jurnal yang ditulis oleh Balbo dan Vigliotti (2013) mengenai "On the Analysis of a M/M/1 Queue with Bulk Service", pada jurnal tersebut secara spesifik membahas mengenai penurunan rumus dari model $M / M^{B} / 1$ dan menjelaskan beberapa kondisi khusus yang dimilki oleh model $M / M^{B} / 1$. Diagram transisi model ini ditunjukkan oleh Gambar 2 berikut. 


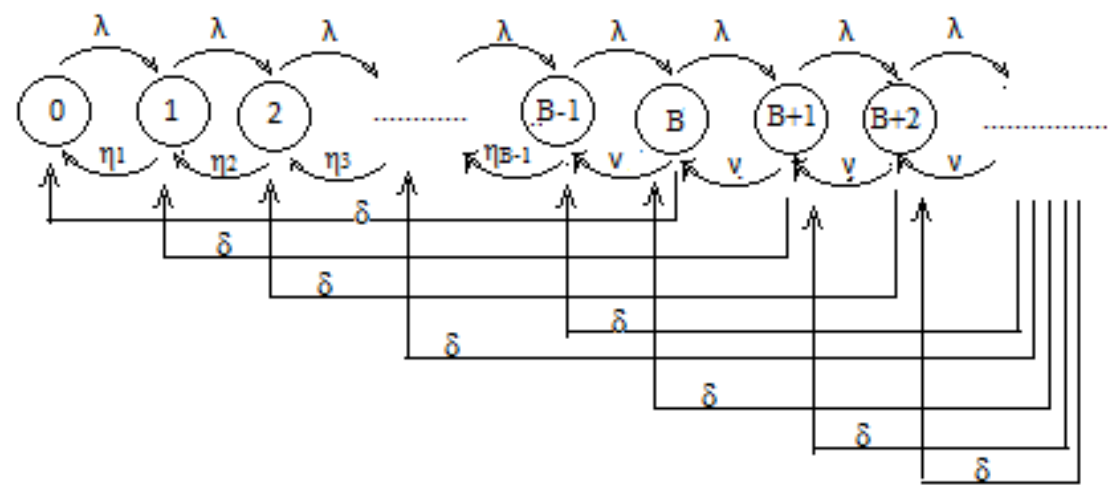

Gambar 2. Diagram Transisi Model $M / M^{B} / 1$

Pada model umum antrian $M / M^{B} / 1$ terdapat kondisi dimana pengguna keluar dari sistem secara satu per satu sedangkan banyaknya pengguna yang masih berada dalam sistem sebanyak kurang dari ukuran Bulk atau dapat dituliskan dengan $\eta_{1}, \eta_{2}, \ldots, \eta_{B-1}$ Pada kondisi lain pengguna akan keluar secara satu per satu apabila banyaknya pengguna di dalam sistem melebihi ukuran Bulk dimana dapat dituliskan dengan $v$, sedangkan $\delta$ menunjukkan bahwa sekelompok pengguna (Bulk) meninggalkan sistem. Berdasarkan uraian di atas maka didapat Global Balance Equation ( $G B E$ ) yang dimiliki oleh model antrian $M / M^{B} / 1$ seperti penjabaran berikut

$$
\begin{array}{lll}
\text { State } 0 & \rightarrow \lambda \pi_{0} & =\eta_{1} \pi_{1}+\delta \pi_{B} \\
\text { State 1 } & \rightarrow \pi_{1}\left(\lambda+\eta_{1}\right) & =\lambda \pi_{0}+\eta_{2} \pi_{2}+\delta \pi_{B-1} \\
\text { State 2 } & \rightarrow \pi_{2}\left(\lambda+\eta_{2}\right) & =\lambda \pi_{1}+\eta_{3} \pi_{3}+\delta \pi_{B-2}
\end{array}
$$

State $B-2 \rightarrow \pi_{B-2}\left(\lambda+\eta_{B-2}\right)=\lambda \pi_{B-3}+\eta_{B-1} \pi_{B-1}+\delta \pi_{2 B-2}$

State $B-1 \rightarrow \pi_{B-1}\left(\lambda+\eta_{B-1}\right)=\lambda \pi_{B-2}+v \pi_{B}+\delta \pi_{2 B-1}$

State $B$

$$
\rightarrow \pi_{B}(\lambda+v+\delta)=\lambda \pi_{B-1}+v \pi_{B+1}+\delta \pi_{2 B}
$$

State $B+k \rightarrow \pi_{B}+k(\lambda+v+\delta)=\lambda \pi_{B+k-1}+v \pi_{B+k-1}+\delta \pi_{2 B+k}$

Bentuk umum dari persamaan (1) dapat dituliskan sebagai berikut (Balbo dan Vigliotti, 2013) 
$\frac{\sum_{x=1}^{y-1} \pi(B+1)+x}{\pi_{y}} \delta=\phi_{\mathrm{y}}$

$0 \leq y \leq B-2$

$\frac{\sum_{x=1}^{B-1} \pi(m+1)+x}{\pi_{m}} \delta=\psi_{\mathrm{m}}$

$m \geq B-1$

Secara rekursif, persamaan (2) dapat dituliskan ulang sebagai (Balbo dan Vigliotti, 2013)

$\pi_{\mathrm{n}}= \begin{cases}\pi_{0}\left[\prod_{j=1}^{n} \frac{\lambda-\phi_{j-1}}{\eta_{j}}\right] & n \leq B-1 \\ \pi_{0}\left[\prod_{j=1}^{B-1} \frac{\lambda-\phi_{j-1}}{\eta_{j}}\right]\left[\prod_{j=1}^{n} \frac{\lambda-\varphi_{j-1}}{(v+\delta)}\right] & n \geq B\end{cases}$

Berdasarkan persamaan (3.6) maka dapat dituliskan sebagai berikut berikut

$\pi_{\mathrm{n}}= \begin{cases}\pi_{0}\left[\prod_{j=1}^{n} \sigma_{j}\right] & n \leq B-1 \\ \pi_{0}\left[\prod_{j=1}^{B-1} \sigma_{j}\right] \rho^{n-B+1} & n \geq B\end{cases}$

dengan

$\sigma_{j}=\frac{\left(\lambda-\phi_{j-1}\right)}{\eta_{j}}$,

$n \leq B-1$

$\rho=\frac{(\lambda-\psi)}{(\nu+\delta)}$,

$n \geq B$

Selanjutnya, $\pi_{0}$ dengan menggunakan persamaan seperti berikut:

$\pi_{0}=\left[1+\sum_{i=1}^{B-1}\left[\prod_{i=1}^{n} \sigma_{i}\right]+\left[\prod_{i=1}^{B-1} \sigma_{i}\right] \frac{\rho}{1-\rho}\right]^{-1}$ 
Dalam antrian Bulk Service terdapat dua kondisi yang dianggap konstan yaitu:

1. Kondisi ketika $\eta_{i}=\eta=\mu$

Kondisi ini menganggap bahwa ketika pengguna secara satu per satu keluar dari sistem dengan jumlah pengguna yang ada dalam sistem yaitu kurang dari $B$, dianggap memiliki keadaan yang sama dengan $\mu$ atau keadaan bahwa (keseluruhan) laju layanan konstan, terlepas dari jumlah pengguna meninggalkan server setelah selesai layanan.

2. Kondisi ketika $\eta_{i}=\eta=v$

Sesuai dengan fakta bahwa pengguna tunggal disimbolkan dengan tingkat yang sama, terlepas dari fakta bahwa jumlah pengguna di server lebih besar atau lebih kecil dari $B$.

Berikut merupakan rumus untuk mencari kinerja antrian pada model antrian dengan Bulk Service:

i. Rata-rata banyaknya pengguna dalam antrian $(L q)$

$$
L q=\sum_{n=1}^{\infty} n \pi_{n}
$$

ii. Rata-rata waktu yang dihabiskan seorang pelanggan dalam antrian $(W q)$

$$
W q=\frac{L q}{\lambda}
$$

iii. Rata-rata waktu yang dihabiskan seorang pelanggan dalam sistem (Ws)

$$
W s=W q+\frac{1}{\mu}
$$

iv. Rata-rata banyaknya pengguna dalam sistem $(L s)$

$$
L s=W s \times \lambda
$$

\section{HASIL DAN PEMBAHASAN}

Berikut adalah nilai-nilai dari notasi dasar yang digunakan dalam perhitungan kinerja sistem antrian pada penelitian ini 
Tabel 2. Nilai Notasi Dasar Perhitungan Kinerja Antrian

\begin{tabular}{|c|c|c|}
\hline Notasi & Pengertian & Nilai \\
\hline$\lambda$ & $\begin{array}{l}\text { Rata - rata kedatangan pengguna } \\
\text { atau dalam kasus ini pengguna } \\
\text { internet yang log-in kedalam } \\
\text { sistem }\end{array}$ & $\begin{array}{c}3,0366 \approx 3 \text { pengguna per } \\
\text { menit }\end{array}$ \\
\hline$\mu$ & $\begin{array}{l}\text { Tingkat layanan total sistem } \\
\text { ketika memuat setidaknya } B \\
\text { pengguna }\end{array}$ & $\begin{array}{c}2,4453 \approx 2 \text { pengguna per } \\
\text { menit }\end{array}$ \\
\hline$B$ & $\begin{array}{l}\text { Pengguna Wifi UIIAccess yang } \\
\text { keluar secara berkelompok }\end{array}$ & 27 orang per menit \\
\hline$p$ & $\begin{array}{l}\text { Peluang bahwa penyelesaian } \\
\text { layanan melibatkan Bulk atau } \\
\text { kelompok pengguna }\end{array}$ & 0,0305 \\
\hline$q$ & $\begin{array}{l}\text { Peluang bahwa penyelesaian } \\
\text { layanan melibatkan satu } \\
\text { pengguna ketika setidaknya ada } \\
B \text { pengguna di dalam server }\end{array}$ & 0,9694 \\
\hline$v$ & $\begin{array}{l}\text { Tingkat dimana pengguna } \\
\text { meninggalkan sistem sendiri } \\
\text { ketika lebih dari Bulk pengguna } \\
\text { masih ada di dalam sistem }\end{array}$ & $\begin{aligned} \mu \cdot q & =2,4453 \cdot 0,9694 \\
& =2,3707\end{aligned}$ \\
\hline$\delta$ & $\begin{array}{l}\text { Tingkat di mana sekelompok } \\
\text { pengguna }(B u l k) \text { meninggalkan } \\
\text { sistem }\end{array}$ & $\begin{aligned} \mu \cdot p & =2,4453 \cdot 0,0305 \\
& =0,0746\end{aligned}$ \\
\hline$\rho$ & Tingkat intensitas pelayanan & 0,92827 \\
\hline
\end{tabular}

Pada penelitian ini menggunakan kondisi ketika $\eta_{i}=\mu$ yaitu menganggap bahwa ketika pengguna secara satu per satu keluar dari sistem dengan jumlah pengguna yang ada dalam sistem yaitu kurang dari Bulk, dianggap memiliki keadaan yang sama dengan $\mu$ atau keadaan bahwa (keseluruhan) Server rate 
konstan, terlepas dari jumlah pengguna meninggalkan server setelah selesai layanan. Akibatnya, didapat $\hat{\sigma}_{B-1}$ dan $\hat{\sigma}_{i}$ yaitu sebagai berikut

\begin{tabular}{|c|c|c|c|}
\hline$i$ & $\hat{\sigma}_{i}$ & $i$ & $\hat{\sigma}_{i}$ \\
\hline 1 & 1,203479 & $\mathbf{1 4}$ & 1,025135 \\
\hline 2 & 1,156845 & $\mathbf{1 5}$ & 1,021653 \\
\hline 3 & 1,12574 & $\mathbf{1 6}$ & 1,018286 \\
\hline 4 & 1,103554 & $\mathbf{1 7}$ & 1,014924 \\
\hline 5 & 1,086955 & $\mathbf{1 8}$ & 1,011447 \\
\hline 6 & 1,074083 & $\mathbf{1 9}$ & 1,007716 \\
\hline 7 & 1,063814 & $\mathbf{2 0}$ & 1,003562 \\
\hline 8 & 1,055428 & $\mathbf{2 1}$ & 0,998769 \\
\hline 9 & 1,048441 & $\mathbf{2 2}$ & 0,993051 \\
\hline 10 & 1,04251 & $\mathbf{2 3}$ & 0,986017 \\
\hline 11 & 1,037387 & $\mathbf{2 4}$ & 0,97711 \\
\hline 12 & 1,032881 & $\mathbf{2 5}$ & 0,965504 \\
\hline 13 & 1,02884 & $\mathbf{2 6}$ & 0,949933 \\
\hline
\end{tabular}

Peluang ketika tidak terdapat pengguna dalam sistem $\left(\pi_{0}\right)$ yaitu 0,009980 dan Peluang tertinggi yaitu ketika terdapat 20 pengguna dalam sistem $\left(\pi_{20}\right)$ yaitu sebesar 0,0302 .

Berikut merupakan hasil kinerja antrian untuk wifi UII Access

i. Rata-rata banyaknya pengguna yang ada dalam antrian

$$
\begin{aligned}
L q & =\sum_{i=0}^{\infty} n \pi_{i} \\
& =\left(\sum_{i=0}^{B-1} n \pi_{0}\left[\prod_{j=1}^{i} \sigma_{j}\right]\right)+\left(\sum_{i=0}^{B-1} n \pi_{0}\left[\prod_{j=1}^{B-1} \sigma_{j}\right] \rho^{n-B+1}\right) \\
& =\left(\sum_{i=0}^{26} n \pi_{0}\left[\prod_{j=1}^{i} \sigma_{j}\right]+\left(\sum_{i=0}^{B-1} n \pi_{0}\left[\prod_{j=1}^{26} \sigma_{j}\right] \rho^{n-B+1}\right)\right.
\end{aligned}
$$




$$
=11.04323 \approx 11 \text { pengguna per menit }
$$

ii. Rata-rata waktu yang dihabiskan pengunjung di dalam antrian

$$
\begin{aligned}
& \mathrm{Wq}=\frac{L q}{\lambda} \\
& \mathrm{Wq}=\frac{31,7506}{3,0366}=3.63663 \text { menit per pengguna }
\end{aligned}
$$

iii. Rata-rata Rata-rata waktu yang dihabiskan pengunjung di dalam antrian

$$
\begin{aligned}
\mathrm{Ws} & =\mathrm{Wq}+\mathrm{E}(\mathrm{S}) \\
& =\mathrm{Wq}+(\mathrm{E}(\mathrm{S} \mid \mathrm{I}) \mathrm{P}(\mathrm{I})+\mathrm{E}(\mathrm{S} \mid \mathrm{B}) \mathrm{P}(\mathrm{B})) \\
& =\mathrm{Wq}+\left(\frac{1}{v} \mathrm{P}(\mathrm{I})+\frac{1}{\delta} \mathrm{P}(\mathrm{B})\right) \\
& =3.63663+\frac{1}{2,3707} \frac{911}{1796}+\frac{1}{0,0746} \frac{885}{1796} \\
& =10.45574 \text { menit per pengguna }
\end{aligned}
$$

iv. Rata-rata banyaknya pengguna yang ada dalam sistem

$$
\begin{aligned}
\mathrm{Ls} & =\lambda \times \mathrm{Ws} \\
& =0,036667 \times 10.45574 \\
& =31.7506 \approx 32 \text { pengguna per menit. }
\end{aligned}
$$

\section{KESIMPULAN DAN SARAN}

\subsection{Kesimpulan}

Pada penelitian ini didapat $\boldsymbol{\rho}$ yaitu 0,92827 yang berarti bahwa $0<\boldsymbol{\rho}<$ 1. Hal tersebut menandakan bahwa fasilitas pelayanan wifi UIIAccess sangat padat karena mendekati nilai 1. Tingkat kinerja antrian wifi UIIAccess berdasarkan hasil yang sudah diteliti dapat dikatakan bahwa kinerja wifi UIIAccess sangat padat dan tidak sebanding dengan pengguna fasilitas yang sangat banyak. Kecepatan wifi yang digunakan pada fasilitas ini juga tidak begitu cepat sehingga banyak pengguna yang banyak menumpuk didalam sistem. Hasil kinerja antrian yang didapat yaitu rata-rata banyaknya pengguna dalam sistem yaitu 32 pengguna per menit, sedangkan rata-rata banyaknya pengguna dalam antrian yaitu 11 pengguna per menit, untuk rata-rata waktu yang dihabiskan seorang pengguna dalam sistem yaitu 10 menit, sedangkan rata-rata waktu yang dihabiskan seorang pengguna dalam antrian yaitu 4 menit. 


\subsection{Saran}

Berdasarkan hasil penelitian dapat disimpulkan bahwa terjadi kepadatan dalam sistem maupun antrian sehingga disarankan bahwa bagian yang menangani sistem informasi dalam kampus UII dapat menambahkan kecepatan koneksi internet dengan cara memberikan pembenahan terhadap fasilitas internet UII walaupun pembenahan tersebut membutuhkan biaya yang tidak sedikit.

\section{DAFTAR PUSTAKA}

Agustinah, T., Probabilitas dan Proses Stokastik, Jakarta, 2014.

Anonim, Sejarah Perkembangan Internet di Indonesia Lengkap, http://www.pattascomputer.org/sejarah-perkembangan-internet-diindonesia/, Diakses pada 12 Maret 2017.

Anonim, Praktikum Stokastik Model Antrian, https://labindustrilanjut.files.wordpress.com/2014/11/modul-teoriantrian.pdf, Diakses pada tanggal 4 April 2017.

APJII, Infografis: Penetrasi \& Perilaku Pengguna Internet Indonesia, Polling Indonesia, 2016.

Arman, Teori Antrian, http://armandjexo.blogspot.co.id/2012/04/teoriantrian.html, Diakses pada tanggal 22 Februari 2017.

Balbo, G. dan Vigliotti, M. G., On The Analysis of a M/M/1 Queue with Bulk Service, The British Computer Society : The Computer Journal, 58(1) (2015).

Daniel, W. W., Statistik Nonparametrik Terapan, P.T. Gramedia, Jakarta, 1989.

Fahrozi, Analisis Penerapan Sistem Antrian untuk Pembayaran Pajak Tahunan Dengan Model M/M/S (Multiple Channel-Single Phase), Skripsi, Jurusan Statistika, FMIPA Universitas Islam Indonesia, Yogyakarta, 2014.

Gross, D dan Harris, C. M., Fundamental of Queueing Theory, Edisi Ketiga, John Wiley and Sons, Inc., 1998.

Heizer, J. dan Render, B., Manajemen Operasi (Operations Management), Edisi Ketujuh, Salemba Empat, Jakarta, 2005. 
Kariyam. Diktat : Pengantar Probabilitas, FMIPA UII Jurusan Statistika, Yogyakarta, 2001.

Kakiay, T. J., Dasar Teori Antrian untuk Kehidupan Nyata, Andi, Yogyakarta, 2004.

Kuntoro, T. P. dan Heriadi, D., Jaringan WI-FI, Yogyakarta, 2005.

Ni'amah, A., Durratun, dan Sugito, Sistem Antrian dengan Prioritas Pelayanan, Jurnal Statistika, Universitas Diponegoro, ISBN 978-979097-142-4, 2011.

Sheldon, M. R., Introduction to Probability Models, Edisi Kesembilan, Elsevier, Inc., California, 2007.

Siagian, P., Penelitian Operasional : Teori dan Praktik, Universitas Indonesia Press, Jakarta, 1987.

Sidharta, L., Internet Informasi Bebas Hambatan, Elex Media Komputindo, Jakarta, 1996.

Strauss, J., El-Ansary, A., dan Frost, R., E-Marketing, Edisi Ketiga, Prestice Hall, Ney Jersey, 2003.

Subagyo, P., Dasar-Dasar Operation Research, BPFE, Yogyakarta, 2010.

Supandi, Proses Kelahiran dan Kematian sebagai Rantai Markov Waktu Kontinu, http://portalgaruda.org/, Diakses pada 3 April 2017.

Suryowati, E., Akses Internet Perguruan Tinggi Masih Rendah, http://travel.kompas.com/read/2014/06/11/1609339/Akses.Internet.Pergur uan.T inggi.Masih.Rendah, Diakses pada 22 Februari 2017.

Taha,H. A., Riset Operasi Suatu Pengantar : Jilid Dua, Edisi Kelima, Binarupa Aksara, Tangerang, 1976.

Walpole, R. E., Ilmu Peluang dan Statistika untuk Insinyur Ilmuwan, Edisi Keempat, Penerbit ITB, Bandung, 1995.

Wulan, E. R. dan Wahyuni, N. S., Model Antrian Multi Server $\left(M^{x} / M / C ; C-\right.$ 1/FCFS) dengan Gangguan Pelayanan dengan Pola Kedatangan Berkelompok, Jurnal Matematika Universitas Islam Indonesia, 9(1) (2015). 
White, J. A., Schmidt, J. W., dan Bennett, G. K., Analysis of Queuing Systems, Academic Press, New York, 1975.

Zulian, Y., Manajemen Kuantitatif Bisnis, BPFE, Yogyakarta, 1993. 
